2018-11-26

\title{
Dynamic instability of channel-section beams under periodic loading
}

\section{Li, Long-yuan}

http://hdl.handle.net/10026.1/12482

10.1080/15376494.2018.1501521

Mechanics of Advanced Materials and Structures

Taylor \& Francis

All content in PEARL is protected by copyright law. Author manuscripts are made available in accordance with publisher policies. Please cite only the published version using the details provided on the item record or document. In the absence of an open licence (e.g. Creative Commons), permissions for further reuse of content should be sought from the publisher or author. 
Received 24 April 2018, Accepted 12 July 2018. To be published in

MECHANICS OF ADVANCED MATERIALS AND STRUCTURES

https://doi.org/10.1080/15376494.2018.1501521

\title{
Dynamic instability of channel-section beams under periodic loading
}

Jue Zhu', Shanguang Qian ${ }^{\mathrm{b}, \mathrm{c}^{*}}$, Long-yuan $\mathrm{Li}^{\mathrm{c}^{*}}$

(a) Faculty of Mechanical Engineering and Mechanics, Ningbo University, Ningbo 315211, PR China

(b) Faculty of Architectural Engineering, Kunming Metallurgy College, Kunming 650033, PR China

(c) School of Engineering, University of Plymouth, Plymouth PL4 8AA, UK

*Corresponding author: 308327174@qq.com,

\begin{abstract}
This paper presents an analytical investigation on the free vibration, static buckling and dynamic instability of channel-section beams when subjected to periodic loading. The analysis is carried out by using Bolotin's method. By assuming the instability modes, the kinetic energy and strain energy of the beam and the loss of the potential of the applied load are evaluated, from which the mass, stiffness and geometric stiffness matrices of the system are derived. These matrices are then used to carry out the analyses of free vibration, static buckling and dynamic instability of the beams. Theoretical formulae are derived for the free vibration frequency, critical buckling moment, and excitation frequency of the beam. The effects of the lateral restraint applied to the flange, the section size of the beam and the static part of the applied load on the variation of dynamic instability zones are also discussed.
\end{abstract}

Keywords: Cold-formed steel; buckling; dynamic instability; vibration; lateral-torsional; beam.

\section{Introduction}

Cold-formed steel (CFS) has been widely used in construction industry. Typical examples include purlins and rails for supporting roof and wall in buildings, racks for supporting storage pallets, structural members used for plane and space trusses, and corrugated sheets used for composite floors. Because of the thin thickness and open section features the CFS members are very susceptible by buckling. The buckling models, which a CFS member can have, include local, distortional and global buckling model, depending on the geometry of the member, the type of loading on the member, and the restraint conditions imposed to the member. Numerous studies have been carried out in recent decades on the local, distortional and global buckling and their corresponding post-buckling behaviour of CFS beams and columns [1-7]. A review presented by $\mathrm{Li}$ [6] summarises the recent development in determining the moment capacity of CFS members with a particular focus on the calculation of bending strength due to local, distortional and lateral-torsional buckling.

Existing research work on CFS purlins and rails showed that the sheeting, which is supported by the CFS members, has a significant influence on the distribution of pre-buckling stresses [8-11], the web crippling [12], the buckling behaviour [13-18], and the post-buckling behaviour [14,19-21] of the members. Although the importance of dynamic response to 
machinery loading and to extreme environmental loads such as wind and earthquakes has been recognised for some time, the current design for the CFS members is still dominated by the static load. It is acknowledged that the presence of a static load on a structure can considerably affect the free vibration characteristics of the structure. On the other hand, the vibration of a structure induced by dynamic loading can also affect the buckling behaviour of the structure. Therefore, it is important to understand the behaviour of structures that work under dynamical loading conditions. In the present paper our work will focus on the dynamic buckling behaviour of CFS members subjected to periodic loading.

Vibration induced buckling of beams has been studied as early as in 1960s. For example, Morris [22] discussed the nonlinear vibration problem of a two hinged beam-column subjected to a harmonic load of any space distribution. The fundamental mode and the dynamic instability region of the system were obtained by using a perturbation method. Huang and Hung [23] investigated the dynamic instability of a simply supported straight beam under periodic axial excitation by using the averaging method and the Routh-Hurwitz stability criteria. Huang [24] and Chen et al. [25] investigated the dynamic instability of generally orthotropic beams and thick bimodulus beams subjected to periodic axial loads, respectively, by using the Bolotin's method. Yeh et al. [26] investigated the dynamic instability problem of a sandwich beam with a constrained layer and an electrorheological fluid core subjected to an axial dynamic force by using the finite element method and the harmonic balance method. They examined the influences of the natural frequencies and static buckling loads on the dynamic instability behaviour. Gürgöze [27] examined the instability behaviour of a pre-twisted beam subjected to a pulsating axial force by using the Mettler method and derived the equations describing the instability regions, which could be applied to beams with various different boundary conditions. Kar and Sujata [28] investigated the dynamic instability of rotating beams with various different boundary conditions, subjected to a pulsating axial excitation, and examined the effects of the boundary conditions and rotational speed on the static buckling loads and the regions of parametric instability. Yoon and Kim [29] analysed the dynamic instability problem of a spinning unconstrained beam with a concentrated mass arbitrarily located on the beam, subjected to a combined static and harmonic load, by using the finite element method. Their results showed that the concentrated mass increased the dynamic stability of the spinning unconstrained beam subjected to a thrust. As the spinning speed of the beam was increased, the instability regions were reduced, but various slight instability regions were additionally developed. Uang and Fan [30] evaluated the cyclic instability of steel moment connections with reduced beam sections. Based on the test results of 55 full-scale specimens, regression analyses were performed to develop the relationships between the response quantities and the slenderness ratios for the local buckling modes of both web and flange. Apart from the straight beams, the dynamic instability of curved beams such as arches subjected to radial and follower distributed loading has been also studied [31-33].

The aforementioned literature survey shows that there have been numerous studies on the dynamic instability of beams. However, most of them are for the beams subjected to periodic axial excitation. For CFS beams frequently used as the secondary beams in buildings the dynamic loads are normally the machinery loading, wind loading and earthquake loading, for which the dynamic buckling mode is dominated by the lateral-torsional buckling. This kind of problems has not been addressed in literature. In this paper the dynamic instability of channel-section beams subjected to periodic loading is investigated. The analysis is carried out by using Bolotin's method. By assuming the dynamic buckling modes, the kinetic energy and strain energy of the beam and the loss of the potential of the applied load are evaluated, 
from which the mass, stiffness and geometric stiffness matrices of the system are derived. These matrices are then used to carry out the analyses of free vibration, static buckling and dynamic instability of the beams.

\section{Governing equations for dynamic instability analysis of channel-section beams}

Consider the dynamic instability of a channel-section beam that is used to support sheeting under the action of a periodic loading, as shown in Fig.1. In the system the load is assumed to act on the sheeting, which is transferred to the beam through the fixings and contact between the sheeting and flange of the channel-section beam. The sheeting in the system provides translational and rotational restraints to the beam due to its membrane and bending rigidities. For most types of sheeting the lateral displacement at the fixing point may be assumed to be fully restrained since the membrane rigidity of the sheet is sufficiently large. However, the rotational restraint depends upon several factors, including the number, type and positions of the screws used for the fixings as well as the dimensions of the beam and sheeting. In the present study, the rotational restraint is ignored due to the weak bending rigidity of the sheeting and thus the corresponding results are considered to be conservative $[8,10,13]$.

The dynamic instability problem of elastic structural members, such as columns and beams, induced by periodic loadings has been discussed by many researchers. Early work on this subject was reported by Evan-Iwanowski [34] and Nayfeh and Mook [35]. Bolotin [36] provided an extensive introduction to the analysis of dynamic stability problems of various structural elements, in which the equation of motion of the structure can be generalised using the matrices of the mass, stiffness, and geometric stiffness of the structure. In the present study, the Bolotin's method is employed, in which the mass and stiffness matrices of the channel-section beam are derived by evaluating the kinetic energy and strain energy of the beam, whereas the geometric stiffness matrix is derived by examining the loss of the potential of the applied load.

Let $x, y$, and $z$ be the three coordinate axes of the right-hand rectangular coordinate system, with $x$ being the longitudinal axis, $y$ and $z$ being the cross-sectional axes parallel to the web and flange lines, respectively. The origin of the coordinates is defined at the shear centre of the section. Note that, for the channel-section beam the centroid point and the shear centre are not at the same point. Let $v$ and $w$ be the transverse and lateral displacement components of the beam at the shear centre, and $\phi$ be the rotation of the beam section (see Fig.1). The kinetic energy and strain energy of the channel-section beam with simply supported boundary conditions due to the transverse displacement, lateral displacement and rotation thus can be expressed as

$$
\begin{aligned}
& T=\frac{\rho A}{2} \int_{o}^{l}\left(\dot{v}^{2}+\dot{w}^{2}\right) d x+\frac{\rho I_{p}}{2} \int_{o}^{l} \dot{\phi}^{2} d x \\
& U=\frac{1}{2} \int_{o}^{l}\left[E I_{y}\left(w^{\prime \prime}\right)^{2}+E I_{z}\left(v^{\prime \prime}\right)^{2}+G J\left(\phi^{\prime}\right)^{2}+E I_{w}\left(\phi^{\prime \prime}\right)^{2}+k_{z}\left(w+\frac{h \phi}{2}\right)^{2}\right] d x
\end{aligned}
$$

where $\rho$ is the density, $A$ is the cross-section area, $I_{p}$ is the polar moment of inertia, $E$ is the Young's modulus, $G$ is the shear modulus, $I_{y}$ and $I_{z}$ are the second moments of area about $y$ and $z$-axis, $J$ is the torsion constant, $I_{w}$ is the warping constant, $k_{z}$ is the artificial spring constant representing the translational restraint of the sheeting applied to the upper flange, $h$ is the web depth, and $l$ is the beam length. It is obvious that $k_{\mathrm{Z}}=0$ represents the case where 
the sheeting has no restraint to the upper flange of the beam, whereas $k_{\mathrm{z}}=\infty$ represents the case where the sheeting produces a lateral restraint to the upper flange of the beam. Note that the dot above a symbol in Eq.(1) represents the derivative of the symbol with respect to time $t$ and the prime of a symbol in Eq.(2) represents the derivative of the symbol with respect to space coordinate $x$.

Note that most channel-section beams are usually used in a pair so that the pre-buckling state of the beam can be treated as only bending about its major axis (i.e. z-axis). Assume that the transverse load is the uplift load acting at the upper flange when the sheeting is fixed with the upper flange (e.g. for wind-induced vibration) or the downward load acting at the lower flange when the sheeting is fixed with the lower flange (e.g. for machinery-induced vibration). In this case, the loss of potential energy of the transverse load $q_{y}$ can be expressed as $[37,38]$,

$$
V=\int_{o}^{l} M_{z} \phi w^{\prime \prime} d x-\frac{a_{y}}{2} \int_{o}^{l} q_{y} \phi^{2} d x
$$

where $q_{y}$ is the distribution load, $M_{z}=q_{y} x(l-x) / 2$ is the pre-buckling internal bending moment, and $a_{y}=h / 2$ is the vertical distance between the loading point and shear centre. The second term in Eq.(3) is attributed to the effect of loading position, which, in the present case, has a positive effect on the stability of the beam and thus will increase the critical buckling load.

Assume that when the dynamic lateral-torsional buckling occurs, the transverse displacement $v$, lateral displacement $w$, and rotation $\phi$ of the beam can be expressed as follows,

$$
\begin{aligned}
& v(x)=q_{1}(t) \sin \frac{\pi x}{l} \\
& w(x)=q_{2}(t) \sin \frac{\pi x}{l} \\
& \phi(x)=q_{3}(t) \sin \frac{\pi x}{l}
\end{aligned}
$$

where $q_{j}(t) \quad(j=1,2,3)$ are the functions of time. The displacement functions assumed here satisfy the boundary conditions of a simply supported beam. According to the Lagrange method, the equations of motion describing the lateral-torsional buckling of the beam can be expressed as follows,

$$
\frac{d}{d t}\left(\frac{\partial L}{\partial \dot{\mathbf{q}}}\right)-\frac{\partial L}{\partial \mathbf{q}}=0
$$

where $L=T-(U-V)$ is the Lagrangian function and $\mathbf{q}=\left\{q_{1}, q_{2}, q_{3}\right\}^{T}$ is the general displacement vector. Substituting Eqs.(1)-(6) into (7), it yields,

$$
[\mathbf{M}]\{\ddot{\mathbf{q}}\}+[\mathbf{K}]\{\mathbf{q}\}-\lambda\left[\mathbf{K}_{\mathbf{g}}\right]\{\mathbf{q}\}=\{\mathbf{0}\}
$$

where $[\mathbf{M}]$ is the mass matrix, $[\mathbf{K}]$ is the elastic stiffness matrix, $\left[\mathbf{K}_{\mathrm{g}}\right]$ is the geometric stiffness matrix, $\{\ddot{\mathbf{q}}\}$ is the generalized acceleration vector, and $\lambda$ is the loading factor. The mass, stiffness, and geometric stiffness matrices are expressed as follows,

$$
[\mathbf{M}]=\left[\begin{array}{ccc}
\frac{\partial^{2} T}{\partial \dot{q}_{1}^{2}} & \frac{\partial^{2} T}{\partial \dot{q}_{1} \partial \dot{q}_{2}} & \frac{\partial^{2} T}{\partial \dot{q}_{1} \partial \dot{q}_{3}} \\
\frac{\partial^{2} T}{\partial \dot{q}_{2} \partial \dot{q}_{1}} & \frac{\partial^{2} T}{\partial \dot{q}_{2}^{2}} & \frac{\partial^{2} T}{\partial \dot{q}_{2} \partial \dot{q}_{3}} \\
\frac{\partial^{2} T}{\partial \dot{q}_{3} \partial \dot{q}_{1}} & \frac{\partial^{2} T}{\partial \dot{q}_{3} \partial \dot{q}_{2}} & \frac{\partial^{2} T}{\partial \dot{q}_{3}^{2}}
\end{array}\right]=\left[\begin{array}{ccc}
m_{11} & 0 & 0 \\
0 & m_{22} & 0 \\
0 & 0 & m_{33}
\end{array}\right]
$$


in which,

$$
\begin{gathered}
{[\mathbf{K}]=\left[\begin{array}{ccc}
\frac{\partial^{2} U}{\partial q_{1}^{2}} & \frac{\partial^{2} U}{\partial q_{1} \partial q_{2}} & \frac{\partial^{2} U}{\partial q_{1} \partial q_{3}} \\
\frac{\partial^{2} U}{\partial q_{2} \partial q_{1}} & \frac{\partial^{2} U}{\partial q_{2}^{2}} & \frac{\partial^{2} U}{\partial q_{2} \partial q_{3}} \\
\frac{\partial^{2} U}{\partial q_{3} \partial q_{1}} & \frac{\partial^{2} U}{\partial q_{3} \partial q_{2}} & \frac{\partial^{2} U}{\partial q_{3}^{2}}
\end{array}\right]=\left[\begin{array}{ccc}
k_{11} & 0 & 0 \\
0 & k_{22} & k_{23} \\
0 & k_{23} & k_{33}
\end{array}\right]} \\
{\left[\mathbf{K}_{g}\right]=\left[\begin{array}{lll}
\frac{\partial^{2} V}{\partial q_{1}^{2}} & \frac{\partial^{2} V}{\partial q_{1} \partial q_{2}} & \frac{\partial^{2} V}{\partial q_{1} \partial q_{3}} \\
\frac{\partial^{2} V}{\partial q_{2} \partial q_{1}} & \frac{\partial^{2} V}{\partial q_{2}^{2}} & \frac{\partial^{2} V}{\partial q_{2} \partial q_{3}} \\
\frac{\partial^{2} V}{\partial q_{3} \partial q_{1}} & \frac{\partial^{2} V}{\partial q_{3} \partial q_{2}} & \frac{\partial^{2} V}{\partial q_{3}^{2}}
\end{array}\right]=\left[\begin{array}{ccc}
0 & 0 & 0 \\
0 & 0 & k_{g 23} \\
0 & k_{g 23} & k_{g 33}
\end{array}\right]}
\end{gathered}
$$

$$
\begin{aligned}
& m_{11}=\frac{\rho A l}{2}, m_{22}=\frac{\rho A l}{2}, m_{33}=\frac{\rho I_{p} l}{2}, k_{11}=\frac{E I_{z} l}{2}\left(\frac{\pi}{l}\right)^{4}, k_{22}=\frac{E I_{y} l}{2}\left(\frac{\pi}{l}\right)^{4}+\frac{k_{z} l}{2}, k_{23}=\frac{k_{z} l h}{4}, \\
& k_{33}=\frac{G J l}{2}\left(\frac{\pi}{l}\right)^{2}+\frac{E I_{w} l}{2}\left(\frac{\pi}{l}\right)^{4}+\frac{k_{z} l h^{2}}{8}, k_{g 23}=-\frac{q_{y} l}{8}\left(1+\frac{\pi^{2}}{3}\right), k_{g 33}=-\frac{q_{y} l h}{4} .
\end{aligned}
$$

The three equations in Eq.(8) represent the motion of the beam in the transverse, lateral and rotational directions. It is apparent from Eqs.(9)-(11) that, only the second and third equations in Eq.(8) are coupled. This means that, as far as the lateral-torsional vibration is concerned; only these two equations need to be examined. Assume that the externally applied load, $q_{y}$, is periodic, in which case the loading factor can be divided into two parts as expressed in Eq.(12),

$$
\lambda=\lambda_{s}+\lambda_{t} \cos \Omega t
$$

where $\lambda_{s}$ and $\lambda_{t}$ are the amplitudes of the static and dynamic parts, respectively, $\Omega$ is the excitation frequency of the dynamic part of the load, and $t$ is the time.

The dynamic instability regions of the structure described by Eq.(8) can be determined by examining periodic solutions with the periods of $T=2 \pi / \Omega$ and $2 T=4 \pi / \Omega$ [36,39-41]. The solution with the period of $2 T$ is of particular importance, representing the primary instability region of the structure, which can be expressed using the form of trigonometric series given by Eq.(13),

$$
\{\mathbf{q}\}=\sum_{k=1,3, \cdots}\left[\left\{\mathbf{a}_{k}\right\} \sin \frac{k \Omega t}{2}+\left\{\mathbf{b}_{k}\right\} \cos \frac{k \Omega t}{2}\right]
$$

where $\left\{\mathbf{a}_{\mathrm{k}}\right\}$ and $\left\{\mathbf{b}_{\mathrm{k}}\right\}$ are the vectors of coefficients of the assumed solution. Substituting Eqs.(12) and (13) into (8) and letting the coefficients of the series associated with $\sin (\Omega t / 2)$ and $\cos (\Omega t / 2)$ be zero, it yields,

$$
\begin{aligned}
& \left([\mathbf{K}]-\frac{2 \lambda_{s}-\lambda_{t}}{2}\left[\mathbf{K}_{\mathbf{g}}\right]-\frac{\Omega^{2}}{4}[\mathbf{M}]\right)\left\{\mathbf{a}_{1}\right\}=\{\mathbf{0}\} \\
& \left([\mathbf{K}]-\frac{2 \lambda_{s}+\lambda_{t}}{2}\left[\mathbf{K}_{\mathbf{g}}\right]-\frac{\Omega^{2}}{4}[\mathbf{M}]\right)\left\{\mathbf{b}_{1}\right\}=\{\mathbf{0}\}
\end{aligned}
$$


For given values of $\lambda_{s}$ and $\lambda_{t}$, one can calculate the two frequencies of $\Omega$ from Eqs.(14) and (15), which represent the boundary of dynamic instability region of the channel-section beams under periodic loading.

\section{Results and discussion}

The frequency of the lateral-torsional vibration of the channel-section beam can be calculated using Eq.(16)

$$
\left\|[\mathbf{K}]-\omega^{2}[\mathbf{M}]\right\|=0
$$

where $\omega$ is the free vibration frequency. Substituting Eqs.(9) and (10) into (16), the following frequency can be obtained:

For beam with no lateral restraint $\left(k_{\mathrm{z}}=0\right)$ :

$$
\begin{aligned}
& \omega_{1}=\left(\frac{\pi}{l}\right)^{2} \sqrt{\frac{E I_{y}}{\rho A}} \\
& \omega_{2}=\left(\frac{\pi}{l}\right)^{2} \sqrt{\frac{G J\left(\frac{l}{\pi}\right)^{2}+E I_{w}}{\rho I_{p}}}
\end{aligned}
$$

For beam with lateral restraint $\left(k_{\mathrm{z}}=\infty\right)$ :

$$
\omega=\left(\frac{\pi}{l}\right)^{2} \sqrt{\frac{G J\left(\frac{l}{\pi}\right)^{2}+E I_{w}+\frac{E I_{y} h^{2}}{4}}{\rho I_{p}+\frac{\rho A h^{2}}{4}}}
$$

The frequencies given by Eqs.(17) and (18) are well-known which can be found from many vibration textbooks. Eqs.(17)-(19) indicate that, for the beam with no lateral restraint the lateral vibration and torsional vibration modes are independent, whereas for the beam with lateral restraint applied at the upper flange the lateral vibration and torsional vibration modes are combined together to form a single mode. As a numerical example, Fig. 2 shows a comparison of the frequencies of a channel-section beam with and without lateral restraint, which also reflects the influence of the lateral restrain on the vibration behaviour of the beam. The material properties used in the numerical example are Young's module $E=210 \mathrm{GPa}$, Poisson ratio $v=0.3$, and density $\rho=7850 \mathrm{~kg} / \mathrm{m}^{3}$. It can be seen from the figure that the frequency of the laterally restrained beam is slight higher than the frequency of the lateral vibration but a little lower than the frequency of the rotational vibration of the unrestrained beam.

The critical load of the lateral-torsional buckling of the channel-section beam subjected to a static load can be calculated using Eq.(20)

$$
\left\|[\mathbf{K}]-\lambda_{c r}\left[\mathbf{K}_{g}\right]\right\|=0
$$

where $\lambda_{c r}$ is the loading factor. Substituting Eqs.(10) and (11) into (20), the following critical load is obtained:

For beam with no lateral restraint $\left(k_{\mathrm{z}}=0\right)$ : 


$$
\left(\frac{q_{y} l^{2}}{8}\right)_{c r}=\frac{\frac{E I_{y} h}{l^{2}}+\sqrt{\left(\frac{E I_{y} h}{l^{2}}\right)^{2}+\frac{E I_{y}}{l^{2}}\left(\frac{G J}{\pi^{2}}+\frac{E I_{w}}{l^{2}}\right)\left(1+\frac{\pi^{2}}{3}\right)^{2}}}{2\left(\frac{1}{3}+\frac{1}{\pi^{2}}\right)^{2}}
$$

For beam with lateral restraint $\left(k_{\mathrm{z}}=\infty\right)$ :

$$
\left(\frac{q_{y} l^{2}}{8}\right)_{c r}=\frac{\left(\frac{\pi}{l}\right)^{2}\left(\frac{E I_{y} h^{2}}{4}+\frac{G J l^{2}}{\pi^{2}}+E I_{w}\right)}{2 h\left(\frac{1}{3}-\frac{1}{\pi^{2}}\right)}
$$

Note that Eq.(21) is identical to the critical load derived by Boksun et al. [42] for a I-section beam when the downwards load is applied at the lower flange if the section properties used in Eq.(22) are calculated based on the I-section beam.

Fig.3 graphically shows a comparison of the critical loads of the channel-section beam with and without lateral restrain, in which the critical moment has been normalized using the yield moment defined as $M_{y}=2 \sigma_{\mathrm{y}} I_{z} / h$ where the yield stress is taken as $\sigma_{\mathrm{y}}=390 \mathrm{MPa}$. It can be seen from the figure that the critical moment of the laterally-restrained beam is marginally higher than that of the unrestrained beam.

The dynamic instability region of the channel-section beam can be calculated using Eq.(23)

$$
\left\|[\mathbf{K}]-\frac{2 \lambda_{s} \pm \lambda_{t}}{2}\left[\mathbf{K}_{\mathbf{g}}\right]-\frac{\Omega^{2}}{4}[\mathbf{M}]\right\|=0
$$

Substituting Eqs.(9)-(11) into (23), it yields,

$$
\frac{\Omega^{2}}{4}=\frac{\left(m_{22} k_{33}^{*}+m_{33} k_{22}\right) \pm \sqrt{\left(m_{22} k_{33}^{*}-m_{33} k_{22}\right)^{2}+4 m_{22} m_{33}\left(k_{23}^{*}\right)^{2}}}{2 m_{22} m_{33}}
$$

where $k_{22}^{*}=k_{22}-\left(\lambda_{s} \pm \frac{\lambda_{t}}{2}\right) k_{g 22}$ and $k_{23}^{*}=k_{23}-\left(\lambda_{s} \pm \frac{\lambda_{t}}{2}\right) k_{g 23}$. For the beam with lateral restraint where $k_{\mathrm{z}}=\infty$, Eq.(24) can be simplified into

$$
\frac{\Omega^{2}}{4}=\frac{\left[\left(\frac{h}{2}\right)^{2}\left(\frac{\pi}{l}\right)^{2} E I_{y}+G J+\left(\frac{\pi}{l}\right)^{2} E I_{w}-2 h\left(\lambda_{s} \pm \frac{\lambda_{t}}{2}\right)\left(\frac{q_{y} l^{2}}{8}\right)_{c r}\left(\frac{1}{3}-\frac{1}{\pi^{2}}\right)\right]\left(\frac{\pi}{l}\right)^{2}}{\rho A\left(\frac{h}{2}\right)^{2}+\rho I_{p}}
$$

It can be noticed that Eq.(24) includes four independent equations, whereas Eq.(25) represents only two independent equations. The reason for this is because, in the former there 
are two vibration modes from which four different $\Omega^{2}$ values can be obtained for each given loading factor; whereas in the later there is only one vibration mode from which only two different $\Omega^{2}$ values can be obtained for each given loading factor.

Fig.4 shows the dynamic instability regions of the channel-section beam of $7 \mathrm{~m}$ length with and without lateral restraint under an uplift periodic load applied at the upper flange of the beam, in which the geometric stiffness matrix is evaluated using the static critical load, that is $q_{y}=q_{c r}$. Note that there are two zones (red and green lines) for the unrestrained beam and one zone (blue lines) for the restrained beam. It can be seen from the figure that, the dynamic instability region of the laterally restrained beam is quite different from that of the unrestrained beam. The former exhibits a standard " $v$ " shape, whereas in the latter one of the two arms in each zone is warped (lines indicated by letter A and B, respectively). This is because the effect of the loading position on the critical load, which is sensitive to the loading direction when the beam is not laterally restrained. When the loading is applied above the shear centre, the uplift load stabilizes the beam whereas the downward load destabilizes the beam. For the laterally restrained beam, however, only the uplift load can cause the beam to buckle. This is why the two lines of the dynamic instability zone of the laterally restrained beam are close to the side lines of the two dynamic instability zones of the unrestrained beam.

Fig.5 shows the dynamic instability region of the laterally restrained channel-section beam of $7 \mathrm{~m}$ length under a combined static and periodic load applied at the upper flange of the beam. It can be seen from the figure that, when a static load of $40 \%$ of the critical load is involved, the dynamic instability zone shifts to lower frequency side and the corresponding width of the instability zone is extended largely.

As an example of parametric study, Figs.6-8 shows the effect of section depth, flange width and lip length on the dynamic instability of the laterally restrained channel-section beam of 7 $\mathrm{m}$ length. It can be seen from Fig.6 that the increase of section depth results in a shaft of the instability zone to lower frequency side and a slight decrease of the width of the instability zone. This is expected as both the vibration and buckling of the laterally restrained beam is dominated by the torsion about the restrained point, in which case the increase of the section depth does not make the section stiffer. However, when the flange width (see Fig.7) or the lip length (see Fig.8) is increased the instability zone is found to shaft to higher frequency side and the width of the instability zone is also slightly increased, which is opposite to the result by increasing the section depth.

Note that, in practice when the section depth is increased the flange width, lip length and section thickness are also increased in order to make the beam more effective in fighting different failure modes. The effect of the overall beam section size on the dynamic instability of the laterally restrained channel-section beam of $7 \mathrm{~m}$ length is shown in Fig.9. It can be observed from the figure that, with the increase of the section size, the dynamic instability zone moves towards to higher frequency side and the corresponding width of the instability zone is also increased remarkably. Herein, it should be noted that, the comparison of the widths of the instability zones for different beam sections shown in Figs.6-9 is made based on the frequencies obtained under a given relative loading factor, which is defined as the applied load divided by the static critical load of that beam. This means that if use the real value plot, the width of the instability zone may not be the same as that plotted in Fig.9.

\section{Conclusions}


This paper has presented an analytical study on the dynamic instability of channel-section beams under the action of periodic loading. By using a combined Lagrange and Bolotin method, analytical expressions for the frequency of free vibration, the critical load of lateral torsional buckling, and the excitation frequency of dynamic instability region have been derived. From the obtained results the following conclusions can be drawn:

- The lateral restraint of the sheeting has a marginal influence on the frequency of free vibration and the critical load of lateral-torsional buckling of the channel-section beam.

- The lateral restraint has a significant effect on the dynamic instability behaviour of the channel-section beam. The dynamic instability zones of the channel-section beam with and without lateral restraint are quite different.

- The increase of the section size of the channel-purlin leads to a shift of the dynamic instability zone towards to higher frequency side and the broad up of the width of the instability zone.

- When the applied load involves a static load the dynamic instability zone will shift towards to lower frequency side and the width of the instability will be also expanded.

- The increase of the section depth results in a shaft of the instability zone to lower frequency side and a slight decrease of the width of the instability zone; whereas the increase of the flange width or lip length results in a shift of the instability zone to higher frequency side and a slight increase of the width of the instability zone.

Acknowledgements - The authors acknowledge the financial support received from National Natural Science Foundation of China (No.11572162). The first author also wishes to acknowledge the 47th Scientific Research Foundation for Returned Scholars from Ministry of Education of China, Natural Science Foundation of Zhejiang Province (No.LY13A020007), and K.C. Wong Magna Fund at Ningbo University for their financial support. The second author wishes to acknowledge the China Scholar Council (CSC) for supporting him to visit the University of Plymouth.

\section{References}

[1] J. M. Davies, "Recent research advances in cold-formed steel structures," Journal of Constructional Steel Research, vol. 55, no. 1-3, pp. 267-288, 2000.

[2] J. Rondal, "Cold formed steel members and structures - general report," Journal of Constructional Steel Research, vol. 55, no. 1-3, pp. 155-158, 2000.

[3] G. J. Hancock, "Cold-formed steel structures," Journal of Constructional Steel Research, vol. 59, no. 4, pp. 473-487, 2003.

[4] M. Macdonald, M. A. Heiyantuduwa and J. Rhodes, "Recent developments in the design of cold-formed steel members and structures," Thin-Walled Structures, vol. 46, no. 7-9, pp. 1047-1053, 2008.

[5] B. W. Schafer, "Review: the direct strength method of cold-formed steel member design," Journal of Constructional Steel Research, vol. 64, no. 7-8, pp. 766-778, 2008.

[6] L. Y. Li, "Calculation of moment capacity of cold-formed steel members," International Journal of Structural Engineering, vol. 2, no. 2, pp. 101-115, 2011.

[7] G. J. Hancock, "Cold-formed steel structures: Research review 2013-2014," Advances in Structural Engineering, vol. 19, no. 3, pp. 1-16, 2016. 
[8] Z. M. Ye, R. Kettle and L.Y. Li, "Analysis of cold-formed zed-purlins partially restrained by steel sheeting," Computers \& Structures, vol. 82, no. 10, pp. 731-739, 2004.

[9] B. Gosowski, E. Kubica and K. Rykaluk, "Analysis of laterally restrained cold-formed Cshape purlins according to Vlasov theory," Archives of Civil and Mechanical Engineering, vol. 15, no. 2, pp. 456-468, 2015.

[10] C. Ren, L. Y. Li and J. Yang, "Bending analysis of partially restrained channel-section purlins subjected to up-lift loadings," Journal of Constructional Steel Research, vol. 72, pp. 254-260, 2012.

[11] L. Y. Li, C. Ren and J. Yang, "Theoretical analysis of partially restrained zed-purlin beams subjected to up-lift loads," Journal of Constructional Steel Research, vol.70, pp. 273279, 2012.

[12] B. Young and G. J. Hancock, "Web crippling of cold-formed unlipped channels with flanges restrained," Thin-Walled Structures, vol. 42, no. 6, pp. 911-930, 2004.

[13] Z. M. Ye, R. Kettle, L. Y. Li and B. W. Schafer, "Buckling behaviour of cold-formed zed-purlins partially restrained by steel sheeting," Thin-Walled Structures, vol. 40, no. 10, pp. 853-864, 2002.

[14] C. Ren, X. Z. Zhao and Y. Y. Chen, "Buckling behaviour of partially restrained coldformed steel zed purlins subjected to transverse distributed uplift loading," Engineering Structures, vol. 114, pp. 14-24, 2016.

[15] W. B. Yuan, S. S. Cheng, L. Y. Li and B. Kim, "Web-flange distortional buckling of partially restrained cold-formed steel purlins under uplift loading," International Journal of Mechanical Sciences, vol. 89, pp. 476-481, 2014.

[16] C. Basaglia, D. Camotim, R. Gonçalves and A. Graça, "GBT-based assessment of the buckling behaviour of cold-formed steel purlins restrained by sheeting," Thin-Walled Structures, vol. 72, pp. 217-229, 2013.

[17] X. T. Chu, R. Kettle and L. Y. Li, "Lateral-torsion buckling analysis of partial-laterally restrained thin-walled channel-section beams," Journal of Constructional Steel Research, vol. 60, no. 8, pp. 1159-1175, 2004.

[18] L. Y. Li, "Lateral-torsional buckling of cold-formed zed-purlins partial-laterally restrained by metal sheeting," Thin-Walled Structures, vol. 42, no. 7, pp. 995-1011, 2004.

[19] E. Pieciorak and M. Piekarczyk, "Analysis of the post-buckling behavior of a purlin built from thin-walled cold-formed C profile," Thin-Walled Structures, vol. 45, no. 10-11, pp. 916920, 2007.

[20] J. Zhu, J. K. Chen and C. Ren, "Numerical study on the moment capacity of zed-section purlins under uplift loading," Structural Engineering and Mechanics, vol. 49, no. 2, pp. 147$161,2014$.

[21] S. Pimpasakdi, F. G. Albermani and S. Kitipornchai, "Interactive analysis and design of cold-formed steel cladding system," Journal of Constructional Steel Research, vol. 60, no. 10, pp. 1409-1423, 2004.

[22] N. F. Morris, "The dynamic stability of beam-columns with a fixed distance between supports," Journal of the Franklin Institute, vol. 280, no. 2, pp. 163-173, 1965.

[23] J. S. Huang and L. H. Hung, "Dynamic stability for a simply supported beam under periodic axial excitation," International Journal of Nonlinear Mechanics, vol. 19, no. 4, pp. 287-301, 1984.

[24] C. C. Huang, "Dynamic stability of generally orthotropic beams," Fibre Science and Technology, vol. 13, no. 3, pp. 187-198, 1980.

[25] L. Y. Chen, P. D. Lin and L. W. Chen, "Dynamic stability of thick bimodulus beams," Computers \& Structures, vol. 41, no. 2, pp. 257-263, 1991. 
[26] J. Y. Yeh, L. W. Chen and C. C. Wang, "Dynamic stability of a sandwich beam with a constrained layer and electrorheological fluid core," Composite Structures, vol. 64, no. 1, pp. 47-54, 2004.

[27] M. Gürgöze, "On the dynamic stability of a pre-twisted beam subject to a pulsating axial load," Journal of Sound and Vibration, vol. 102, no. 3, pp. 415-422, 1985.

[28] R. C. Kar and T. Sujata, "Dynamic stability of a rotating beam with various boundary conditions," Computers \& Structures, vol. 40, no. 3, pp. 753-773, 1991.

[29] S. J. Yoon and J. H. Kim, "A concentrated mass on the spring unconstrained beam subjected to a thrust," Journal of Sound and Vibration, vol. 254, no. 4, pp. 621-634, 2002.

[30] C. M. Uang and C. C. Fan, "Cyclic stability criteria for steel moment connections with reduced beam section," Journal of Structural Engineering, vol. 127, no. 9, pp. 1021-1027, 2001.

[31] M. Farshad, "On lateral-torsional instability of arches subjected to motion-dependent loading," Journal of Sound and Vibration, vol. 53, no. 2, pp. 165-171, 1977.

[32] N. Challamel, C. Casandjian and J. Lerbet, "On the occurrence of flutter in the lateraltorsional instabilities of circular arches under follower loads," Journal of Sound and Vibration, vol. 320, no. 3, pp. 617-631, 2009.

[33] C. S. Chang and D. H. Hodges, "Stability studies for curved beams," Journal of Mechanics of Materials and Structures, vol. 4, no. 7-8, pp. 1257-1270, 2009.

[34] R. M. Evan-Iwanowski, "On the parametric response of structures," Applied Mechanics Review, vol. 18, pp. 699-702, 1965.

[35] A. H. Nayfeh and D. T. Mook, "Nonlinear Oscillations," Wiley, New York, 1979.

[36] V. V. Bolotin, "The Dynamic Stability of Elastic Systems," Holden-Day, San Francisco, 1964.

[37] C. H. Yoo and S. C. Lee, "Stability of structures, principles and applications," Butterworth-Heinemann, Kidlington, Oxford, UK, 2011.

[38] S. P. Timoshenko and J. M. Gere, "Theory of Elastic Stability (2nd edition)," McGrawHill Book Company, New York, 1961.

[39] S. N. Patel, P. K. Datta and A. H. Sheikh, "Buckling and dynamic instability analysis of stiffened shell panels," Thin-Walled Structures, vol. 44, no. 3, pp. 321-333, 2006.

[40] W. B. Kratzig, L. Y. Li and P. Nawrotzki, "Stability conditions for non-conservative dynamical systems," Computational Mechanics, vol. 8, no. 3, pp. 145-151, 1991.

[41] L. Y. Li, "Interaction of forced and parametric loading vibrations," Computers and Structures, vol. 40, no. 3, pp. 615-618, 1991.

[42] B. Kim, L. Y. Li and A. Edmonds, "Analytical solutions of lateral-torsional buckling of castellated beams," International Journal of Structural Stability and Dynamics, vol. 16, no. 8, pp. 1-16, 2016. 


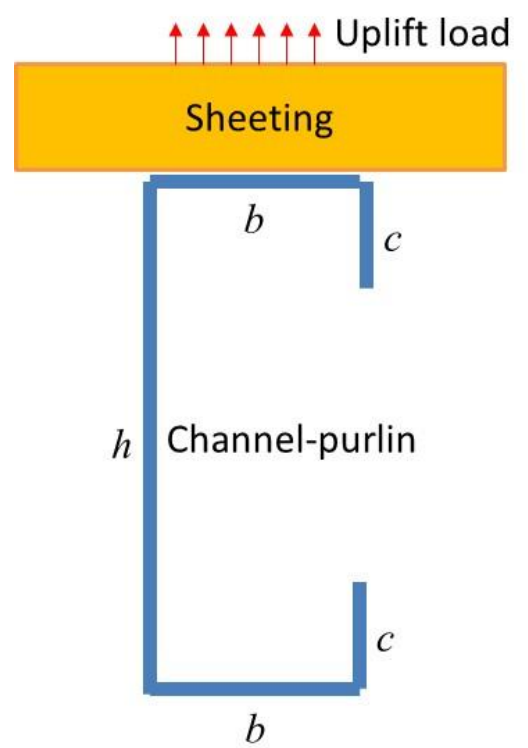

(a)

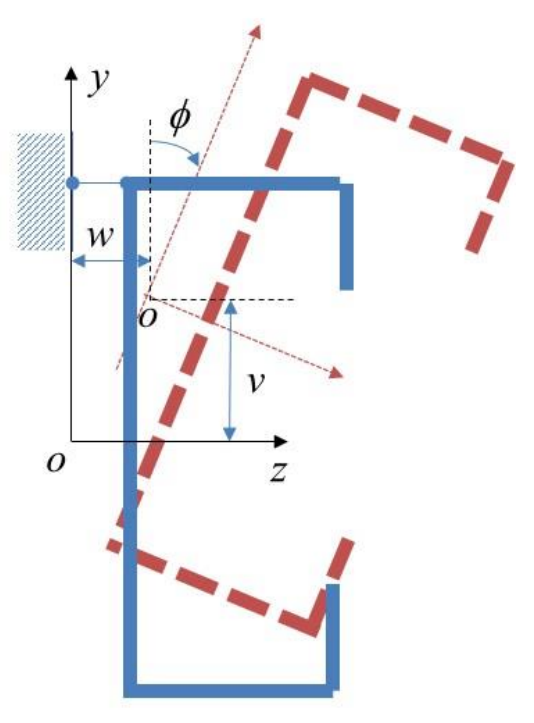

(b)

Figure 1. (a) Sheeting-beam system where $h$ is the web depth, $b$ is the flange width and $c$ is the lip length. (b) Definition of lateral-torsional displacements in beam where $o$ is the shear centre of the channel section.

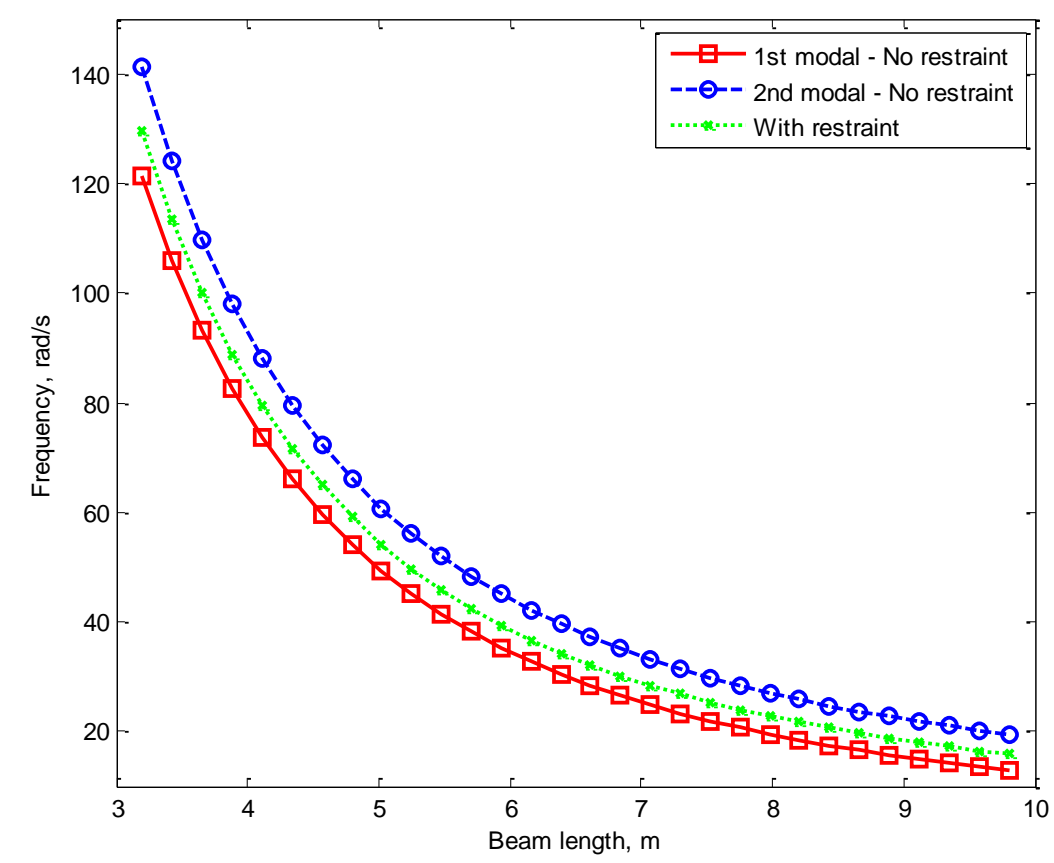

Figure 2. Comparison of frequencies of a channel-section beam with and without lateral restraint (web depth $h=225 \mathrm{~mm}$, flange width $b=65 \mathrm{~mm}$, lip length $c=20 \mathrm{~mm}$, thickness $t=2.0$ $\mathrm{mm})$. 


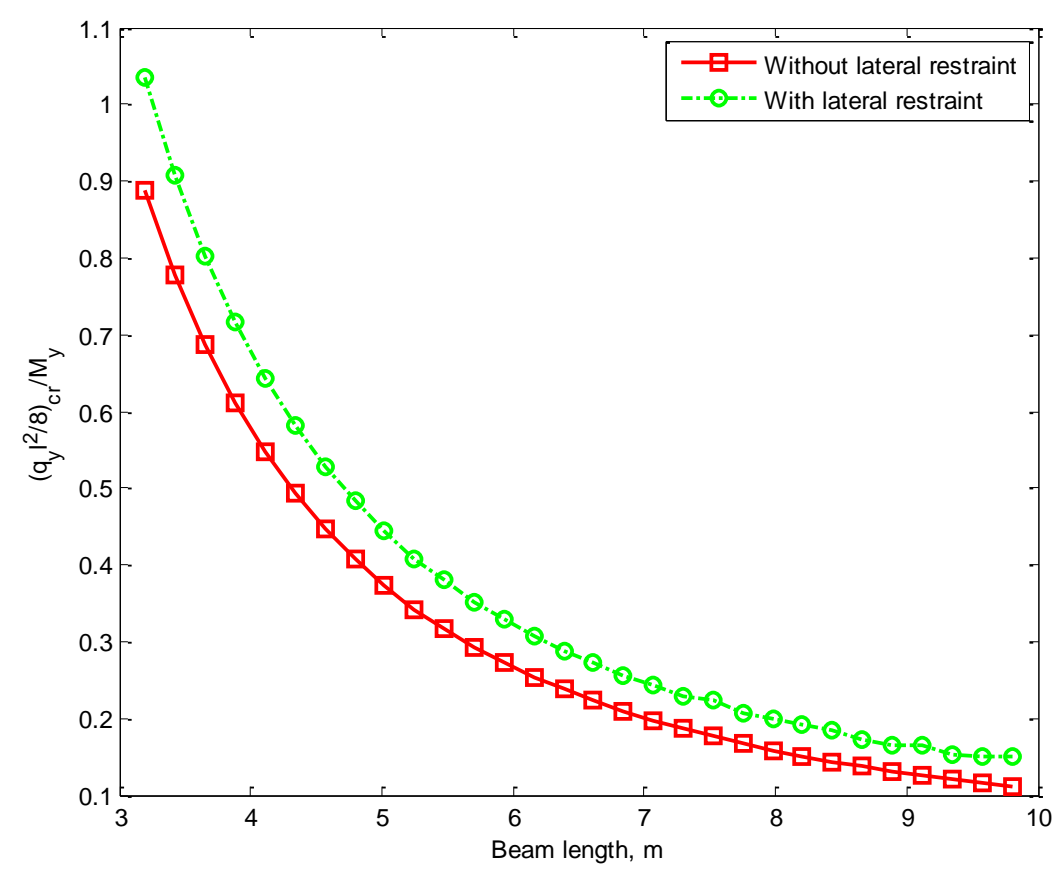

Figure 3. Comparison of critical buckling moments of channel-section beam with and without lateral restraint (web depth $h=225 \mathrm{~mm}$, flange width $b=65 \mathrm{~mm}$, lip length $c=20 \mathrm{~mm}$, thickness $t=2.0 \mathrm{~mm})$.

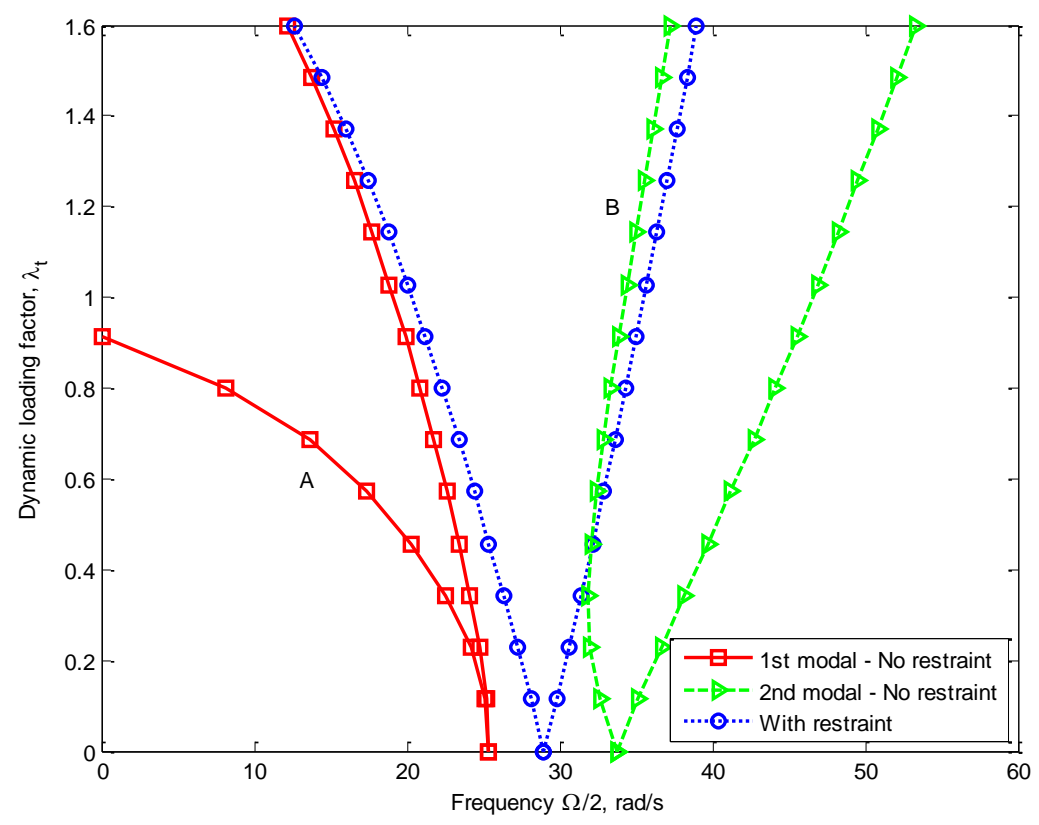

Figure 4. Comparison of dynamic instability regions of channel-section beam with and without lateral restraint (web depth $h=225 \mathrm{~mm}$, flange width $b=65 \mathrm{~mm}$, lip length $c=20 \mathrm{~mm}$, thickness $t=2.0 \mathrm{~mm}$ ). 


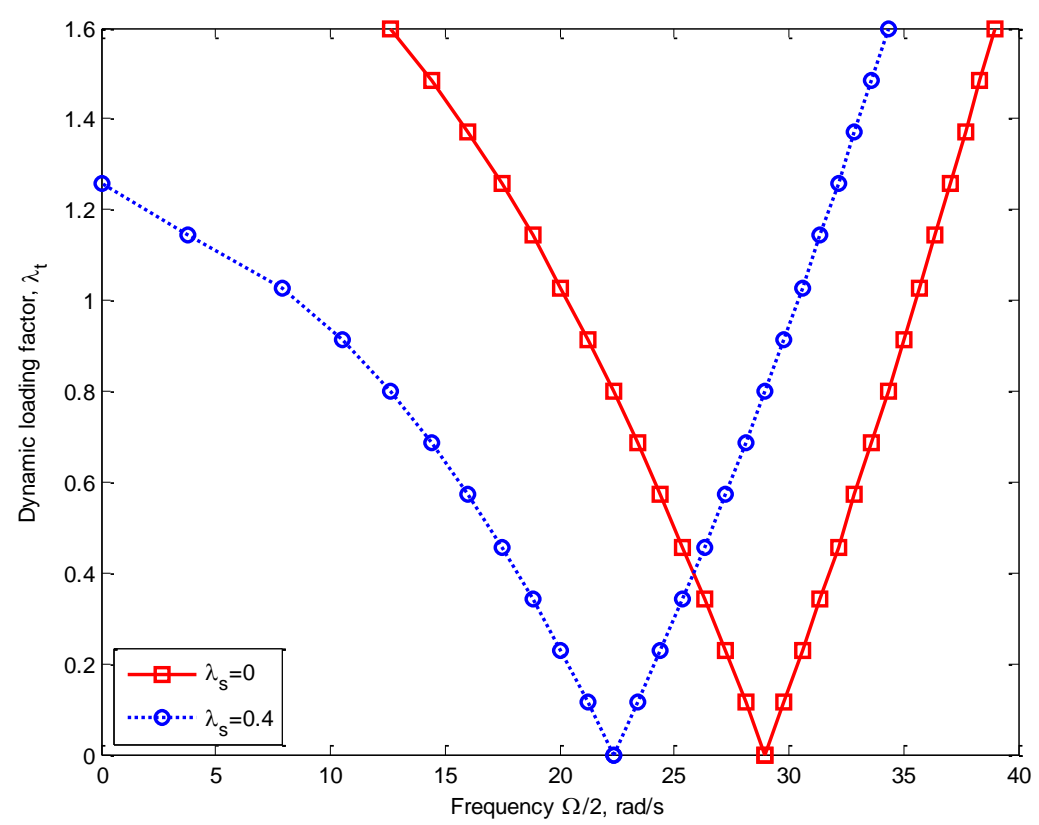

Figure 5. Influence of static loading on dynamic instability region of channel-section beam with lateral restraint (web depth $h=225 \mathrm{~mm}$, flange width $b=65 \mathrm{~mm}$, lip length $c=20 \mathrm{~mm}$, thickness $t=2.0 \mathrm{~mm}$ ).

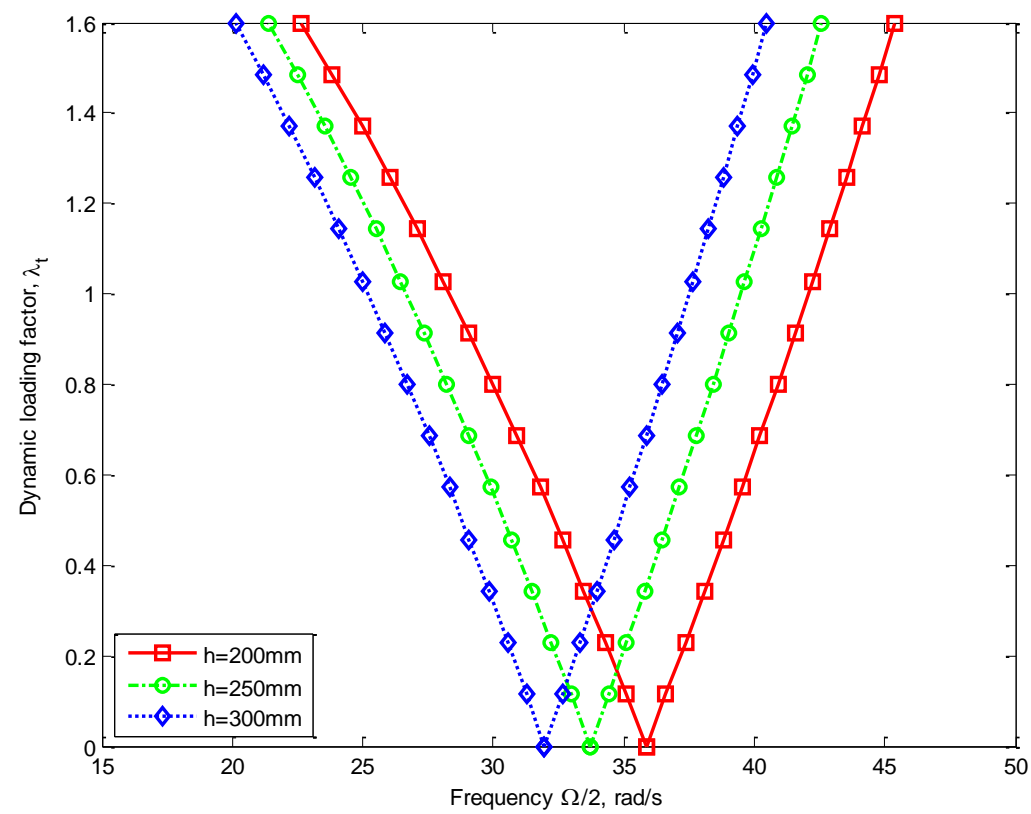

Figure 6. Effect of section depth on dynamic instability of channel-section beams with lateral restraint (Young's module $E=210 \mathrm{GPa}$, Poisson ratio $v=0.3$, density $\rho=7850 \mathrm{~kg} / \mathrm{m}^{3}, b=65 \mathrm{~mm}$, $c=20 \mathrm{~mm}, t=2.5 \mathrm{~mm})$. 


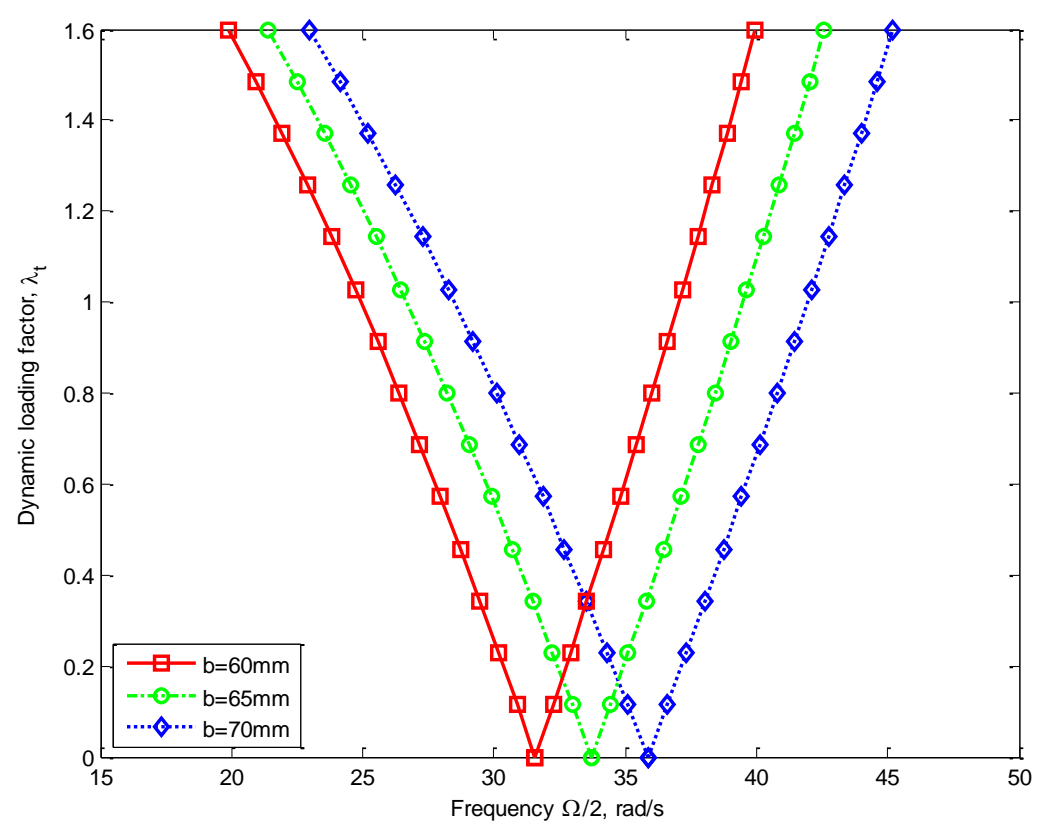

Figure 7. Effect of flange width on dynamic instability of channel-section beams with lateral restraint (Young's module $E=210 \mathrm{GPa}$, Poisson ratio $v=0.3$, density $\rho=7850 \mathrm{~kg} / \mathrm{m}^{3}, h=250$ $\mathrm{mm}, c=20 \mathrm{~mm}, t=2.5 \mathrm{~mm}$ ).

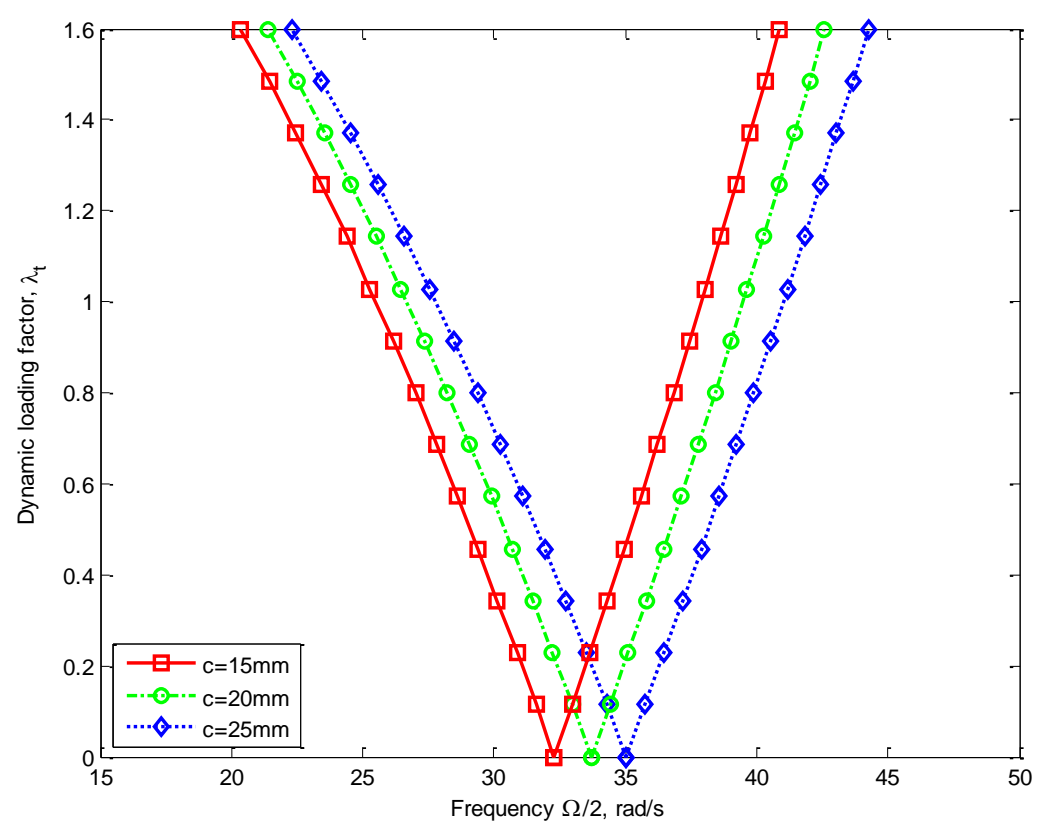

Figure 8. Effect of lip length on dynamic c instability of channel-section beams with lateral restraint (Young's module $E=210 \mathrm{GPa}$, Poisson ratio $v=0.3$, density $\rho=7850 \mathrm{~kg} / \mathrm{m}^{3}, h=250$ $\mathrm{mm}, b=65 \mathrm{~mm}, t=2.5 \mathrm{~mm})$. 


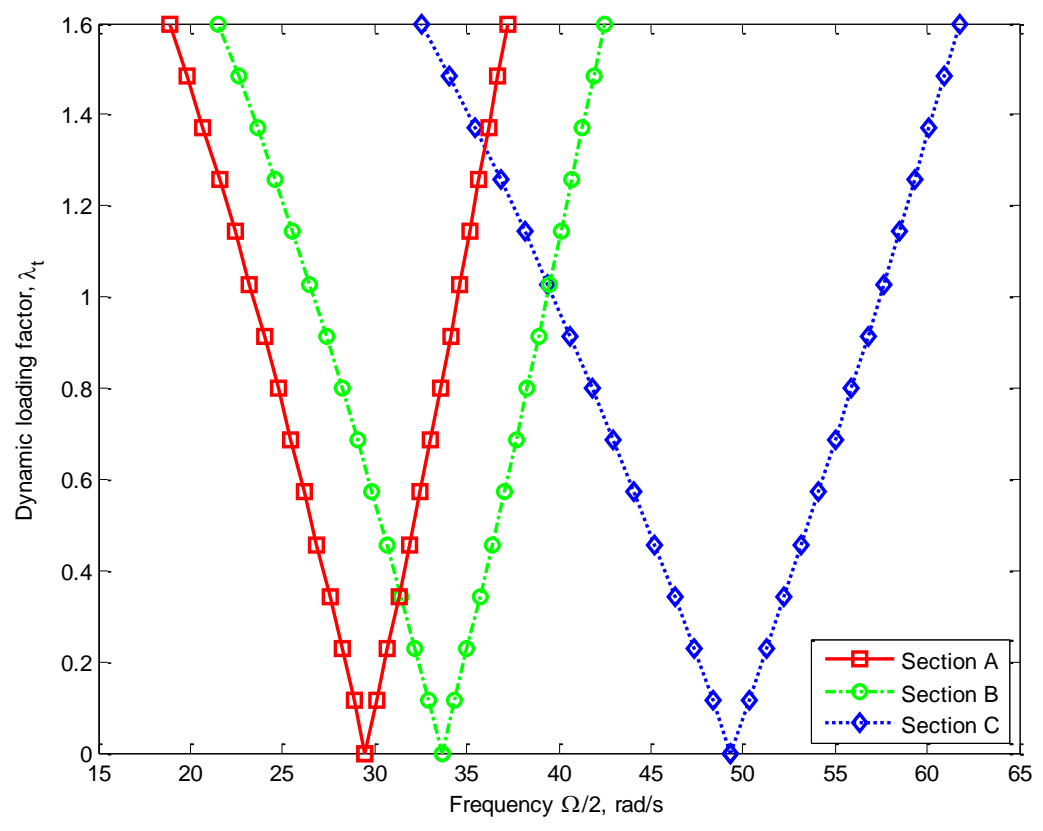

Figure 9. Dynamic instability regions of channel-section beams with lateral restraint (Young's module $E=210 \mathrm{GPa}$, Poisson ratio $v=0.3$, density $\rho=7850 \mathrm{~kg} / \mathrm{m}^{3}$ ). Section A: ( $h=120 \mathrm{~mm}, b=50 \mathrm{~mm}, c=15 \mathrm{~mm}, t=1.5 \mathrm{~mm})$, Section B ( $h=225 \mathrm{~mm}, b=65 \mathrm{~mm}, c=20 \mathrm{~mm}$, $t=2.0 \mathrm{~mm}$ ). Section C ( $h=345 \mathrm{~mm}, b=100 \mathrm{~mm}, c=30 \mathrm{~mm}, t=2.5 \mathrm{~mm})$. 